\title{
Greening crowdfunding campaigns: an investigation of message framing and effective communication strategies for funding success
}

\author{
Monica Rossolini \\ Department of Business and Law, University of Milano-Bicocca, Milan, Italy \\ Alessia Pedrazzoli \\ Department of Economics, University of Modena and Reggio Emilia, \\ Modena, Italy, and \\ Alessandro Ronconi \\ Department of Business and Law, University of Milano-Bicocca, Milan, Italy
}

\begin{abstract}
Purpose - Recognising the growing importance of environmental and sustainable activities and the role of communication strategies in soliciting their financing, this work investigates the influence of message framing, green emphasis and quantitative information on the probability of green crowdfunding campaigns' success.

Design/methodology/approach - This analysis is based on crowdfunding campaigns published between 2015 and 2020 on the Indiegogo platform in the category "Community projects - Environment". The study develops an in-depth qualitative content analysis of the projects before performing an empirical examination to determine funding causes.

Findings - Communication strategies (message framing, green emphasis and quantitative goals) affect funding success. However, project category moderates the impact of message framing and green emphasis on campaign success. While positive framing increases agri-food campaign success, negative framing is more effective for clean energy and climate preservation projects. Moreover, indication of a quantitative goal and a marked green emphasis in a project's presentation increase campaign success, but a too marked green emphasis is only effective for agri-food projects.

Practical implications - Green entrepreneurs and campaign managers must work carefully on their projects' communication, accounting for the type of product proposed, emphasising green components in its description and utilising quantitative information to present future goals. These strategies maximise backers' responses and enable entrepreneurs to obtain funding. The authors' findings may be extended to other contexts, including the banking sector, to craft effective communication strategies for green financial products.

Originality/value - By applying framing theory in a new context (i.e. the online financing of green entrepreneurs), this study identifies new campaign success determinants and provides evidence for the moderating role of project category. Furthermore, the study highlights the need to develop different communication strategies for social and environmental-oriented projects.
\end{abstract}

Keywords Communication, Crowdfunding, Entrepreneurial finance, Green marketing, Message framing, Sustainability

Paper type Research paper

(C) Monica Rossolini, Alessia Pedrazzoli and Alessandro Ronconi. Published by Emerald Publishing Limited. This article is published under the Creative Commons Attribution (CC BY 4.0) licence. Anyone may reproduce, distribute, translate and create derivative works of this article (for both commercial and non-commercial purposes), subject to full attribution to the original publication and authors. The full terms of this licence may be seen at http://creativecommons.org/licences/by/4.0/legalcode
Greening crowdfunding campaigns

Received 29 January 2021 Revised 11 May 2021 Accepted 16 June 2021 
IJBM 39,7

\section{Introduction}

Growing international concerns about environmental sustainability and climate change are propelling the implementation of green innovations and the rise of environmentally sustainable companies (European Commission, 2019). These developments, in turn, contribute to the creation of new products and technologies that aim to mitigate the environmental risks and negative consequences of resource exploitation (Castellacci and Lie, 2017; Spielman, 2020). Recognising the financial sector as a "change maker" for accelerating and mobilising a high level of financial flows from banking, micro-credit, insurance and investment to sustainable-oriented companies, policymakers have established a set of rules to define what is truly sustainable (i.e. a taxonomy of sustainable investments) and avoid greenwashing and the dispersion of financial resources in brown projects. Nevertheless, a lack of sufficient funds continues to pose challenges for the implementation of environmental and sustainable solutions (Karimi Takalo et al., 2021; Wakeford et al., 2017; European Commission, 2018). Sometimes, for example, the financial characteristics of a firm and/or a project (e.g. at the seed stage) - even a project with strong green attributes - hinder traditional financial intermediaries from providing sufficient financial resources.

However, the rise of the fintech industry, where technology is applied to financial activities (Leong, 2018), offers new tools and intermediaries, such as crowdfunding platforms, that are particularly suitable for supporting the financing needs of this type of business (Calic and Mosakowski, 2016; Cumming et al., 2017; Kim and Hall, 2021; Messeni Petruzzelli et al., 2019; Testa et al., 2019). Crowdfunding is an "an open call, essentially through the internet, for the provision of financial resources either in form of donation or in exchange for some form of reward and/or voting rights in order to support initiatives for specific purposes" (Schwienbacher and Larralde, 2012, p. 4). On crowdfunding platforms, entrepreneurs connect directly with investors without involving a traditional financial intermediary; this simple but striking idea distinguishes crowdfunding from banks and professional equity investors (business angels and venture capitalists). Nevertheless, crowdfunding platforms also attract these financial actors to increase strategic competencies that are required in project scouting and risk evaluation (Cosma et al., 2021; Mason et al., 2019).

In addition to fundraising, crowdfunding offers green entrepreneurs' other benefits, such as supplementary information from the target market, early feedback for products that have not yet been marketed and public and social media attention (Belleflamme et al., 2014; Gerber and Hui, 2013). Therefore, crowdfunding influences the credibility of sustainability attributes via perceptions of the quality, fairness and environmental friendliness of the crowdfunded project (Wehnert et al., 2019).

Effective communication strategies are essential in presenting and promoting a crowdfunding campaign on the platform (Manning and Bejarano, 2017). For example, the presence of predictive phrases in project descriptions (Mitra and Gilbert, 2014) and the use of positive, precise and interactive language during the campaign (e.g. Kaminski and Hopp, 2020; Koh et al., 2020; Parhankangas and Renko, 2017) are characteristics that increase funding chances and the number of backers involved.

One persuasive strategy that can be applied in the crowdfunding context and that may be particularly suitable for communicating the value of green initiatives is message framing (Maniatis, 2016). Indeed, the way a campaign goal is labelled or framed may significantly influence individuals' judgments and decisions (Levin et al., 1998). Using positive or negative frames, campaign goals are presented to focus attention on either the potential of the entrepreneurial project to provide environmental benefits (a positive frame) or its potential to reduce environmental loss (a negative frame). Message framing has been studied from various perspectives and in different promotional scenarios, including advertising for bank credit cards, mortgages, charitable giving, transport and consumer products (Avineri and Owen, 2013; Chang and Lee, 2009; Das et al., 2008; Dobson and Poels, 2020; Hauff et al., 2014; 
Nabi et al., 2018; Olsen et al., 2014; Song et al., 2019; Zubair et al., 2020). Nevertheless, research on positive versus negative framing messages within the context of funding activities of green entrepreneurs is limited (Pan et al., 2020; Xu and Huang, 2020), as is research on its application in crowdfunding campaigns.

The aim of this paper is to verify the impact of particular communication strategies on green crowdfunding campaign success. Our work investigates the effects of positive vs negative framing, green emphasis and the communication of a quantitative goal on the probability of green campaign success. In particular, we explore the following research questions: Should green entrepreneurs emphasise positively or negatively framed claims? Should entrepreneurs increase green emphasis and quantitative results in their project descriptions? Does the effectiveness of these communication strategies depend on project sector, and if so, how?

In the crowdfunding literature, many authors contribute to the analysis of the impact of communication strategies on campaign success, but only a few recent studies have demonstrated specific interest in green entrepreneurial projects (Butticè et al., 2019; Hörisch, 2018). Existing studies about message framing either fail to focus on green projects (Allison et al., 2015; Moradi and Dass, 2019) or investigate other types of frames such as prosocial frames and strategic linguistic frames (Defazio et al., 2020; Nielsen and Binder, 2020; Testa et al., 2019). For their part, Kuo and Liu (2014) suggest that other factors may moderate the effect of framing and the persuasiveness of campaign messages. However, the need remains for a deeper understanding of message framing (i.e. positive and negative framing) in the context of green crowdfunding projects' success. Additional research is also required to understand whether specific types of project sectors could moderate framing's effect.

Our paper fills a gap in the extant literature regarding the funding communication strategies of green entrepreneurs in the fintech era. The scope of our in-depth qualitative content analysis and empirical examination includes 86 crowdfunding campaigns launched between 2015 and 2020 on the Indiegogo crowdfunding platform. Through probit regressions, we analyse the impact of communication strategies on the likelihood of campaign success while controlling for a set of variables (geographical area, years, etc.). Our results demonstrate, first, that projects with a positively framed goal enjoy an increased probability of success, but this positive communication strategy might not be equally persuasive in all conditions; rather, its effects could be moderated by project category. Positive framing increases agri-food campaign success, while negative framing is more effective for clean energy and climate preservation projects. These findings consolidate the stream of studies about the role of message framing in supporting the communication of green products (Amatulli et al., 2019; Borin et al., 2011; Grankvist et al., 2004; KarpinskaKrakowiak et al., 2020) and, specifically, the literature about the role of language in promoting new entrepreneurial projects (Kaminski and Hopp, 2020; Koh et al., 2020; Parhankangas and Renko, 2017; Zhou et al., 2015). Second, our study identifies other communication strategies, including the presence of quantitative results and a marked green emphasis in the project description, that affect the probability of success and thereby function as valuable tools for green companies seeking to attract supporters who are potentially predisposed to green marketing. In addition, a campaign's green emphasis is affected by the project's category: a too marked green emphasis in projects with a purely environmental purpose (climate preservation and clean energy projects) negatively affects campaign success while positively affecting the success of projects with both social and environmental purposes (agricultural projects). In this sense, our results explore new success determinants of green entrepreneurial projects in the crowdfunding context (e.g. Butticè et al., 2019; Hörisch, 2018; Testa et al., 2019, 2020) while offering different considerations regarding pro-social and pro-environmental projects (Calic and Mosakowski, 2016, Nielsen and Binder, 2020).

\section{Greening crowdfunding campaigns}

1397 
IJBM

39,7

1398

Knowing whether some backers are more receptive to particular message frames, quantitative results or an emphasis on green claims is important for the success of the message conveyed. This knowledge might also provide practical insights for entrepreneurs and campaign managers to develop more effective strategies and communication tools that encourage more backers to support green campaigns. The results may also be of interest for banks and other financial institutions to improve their crafting of communication strategies for green financial products and thereby increase awareness of green finance issues amongst key players.

The remainder of the paper proceeds as follows. The next section introduces the theoretical background and develops the research hypotheses. A description of the data and methodology employed in the empirical analysis follows. Subsequently, we present the results of the empirical analysis and a set of robustness checks. The final section discusses the results and concludes the paper by highlighting contributions, limitations and directions for future research.

\section{Theoretical framework and hypotheses development}

Message framing is a persuasive communication strategy based on the presentation of an equivalent message using either a positive or a negative frame to influence individual information processing and promote perceptual, attitudinal and behavioural changes (Chang and Wu, 2015; Van de Velde et al., 2010; Levin et al., 1998). Levin et al. (1998) differentiate among three types of framing: (1) risky choice framing, in which options are framed with different risk levels; (2) attribute framing, in which a single attribute or characteristic of an object is framed; and (3) goal framing, in which the consequences of behaviour are framed. The effects of these three types of framing on intentional behaviour differ as do the explanations researchers offer for the relative effectiveness of positive/negative frames. The most frequently adopted theory to guide risk framing message research is prospect theory (Tversky and Kahneman, 1981), which explains that the process underlying the framing effect is related to the unstated but implicit risks that respondents are attempting to pursue or avoid via the recommended behaviour (Nan et al., 2018). Related to this theory is the presence of a negativity bias - or the concept that "loses loom larger than gains", which has been proposed as an explanation for the greater salience of negative framing (Kahneman and Tversky, 1979; Tversky and Kahneman, 1981). For attribute framing, Druckman (2001) refers to "equivalency" information frames in which logically equivalent information not related to an outcome of a risky choice is presented in alternative formats. Consistent with findings regarding the favourable cognitive associations consumers attribute to positive labelling (Levin and Gaeth, 1988; Borin et al., 2011; Dobson and Poels, 2020; Jacobson et al., 2019), positive framing attributes support more favourable evaluations than do negative framing attributes. Goal framing focuses on the evaluation of some situations or behaviours, and in this case, the question is "Which frame, positive or negative, will have the greater persuasive impact in achieving the same end result?" (Levin and Gaeth, 1988, p. 168). Since, in crowdfunding campaigns, green entrepreneurs must present the aim of the project - the "what" for which they are requesting money, we focus on goal framing where positively framed messages highlight gains and the positive environmental consequences associated with project realisation, while negatively framed messages centre around losses and highlight the project's potential to reduce negative environmental consequences. The application of goal framing has been explored across a broad research area, and the effectiveness of positive and negative frames on individual behaviour varies as a function of the task domain (health, consumer products, finance, gambling and social dilemmas), subject characteristics ("expert" or "non-expert" decision-makers; Jacobson et al., 2019) and linguistic and contextual factors (Levin et al., 1998). However, comprehensive meta-analytic reviews 
reveal no robust difference in the persuasive effects of positive vs negative frames. These findings thus caution against a simple generalisations of the results (Nan et al., 2018; Ropret Homar and Knežević Cvelbar, 2021; Xu and Huang, 2020). For example, in the context of charitable advertising, where people must be persuaded to donate for a social cause, results show a slight advantage for positively framed appeals (Chang and Lee, 2009; Das et al., 2008; $\mathrm{Xu}$ and Huang, 2020). Likewise, in the financial service domain, a positive frame is preferred over a negative one (Chuah and Devlin, 2011).

While studies examining goal framing effects in green product communications are limited, the few that exist demonstrate that framing green information positively or negatively can influence pro-environmental behaviour (Chang and $\mathrm{Wu}, 2015$; White et al., 2011) as well as the perceptions and effectiveness of marketing messages (Olsen et al., 2014; Amatulli et al., 2019). The majority of studies suggest that negatively framed messages are more effective (Amatulli et al., 2019; Borin et al., 2011; Grankvist et al., 2004; KarpinskaKrakowiak et al., 2020). Cognitive and emotional mechanisms explain the effectiveness of negative framing in the environmental context. From a cognitive perspective, consumers process negatively framed messages more accurately (Chang et al., 2015; White et al., 2011), while from an emotional perspective, negatively framed messages inspire a sense of anticipated shame and guilt in recipients, fostering the adoption of pro-environmental behaviours (Amatulli et al., 2019; Bilandzic et al., 2017). Others researchers typically turn to prospect theory to explain the positive impact of negative information in terms of unstated but implicit risks that respondents seek to avoid via the proposed environmental behaviour (Ropret Homar and Knežević Cvelbar, 2021).

In the crowdfunding context, proponents are responsible of their projects' descriptions. Thus, they can select positive or negative framing to present the goals of their campaigns. Studies that have applied framing theory to crowdfunding campaigns explore different types of framing (e.g. pro-social, strategic linguistic framing) and find varying evidence of their effects on campaign dynamics. For example, 'Moradi and Dass's (2019) study explores the impact of positive and negative framing on technological Kickstarter projects, revealing that negatively framed messages exert a positive effect on funding levels, which is enhanced by the publication of updates. Allison et al. (2015) examine attribute framing's effects in pro-social lending, finding that positive framing that highlights the venture as an opportunity to help others increases microloan attractiveness and success, while framing the venture as a business opportunity produces a negative effect. Calic and Mosakowski (2016), Defazio et al. (2020) and Testa et al. (2019) explore prosocial frames. Defazio et al. (2020), in particular, evidence how the extent of a campaign's pro-social orientation influences its success, finding that a too strong pro-social orientation reduces a campaign's chances of success, but this negative effect disappears when the platform is extremely crowded. Subsequently, Nielsen and Binder (2020) explore strategic linguistic framing, confirming that campaigns framed toward collective rather than individual benefits receive more financing only when oriented toward social rather than environmental gains.

Although social and environmental entrepreneurs may share common goals and it is sometimes difficult to draw a sharp distinction between the two (Belz and Binder, 2017), a focus on environmental entrepreneurship is critical for improving the understanding of its funding dynamics.

In the reward-based platform analysed for this study, proponents require funds to develop as-yet-undeveloped environmental products/services or to support existing green projects at their inception. From the backers' perspective, supporting a campaign can be viewed as the risky preordering of a product and, at the same time, as a donation, and these perceptions intertwine the extrinsic and intrinsic motivations for backers' decisions (Allison et al., 2015). In this study, green entrepreneurs utilise positively framed messages to highlight the

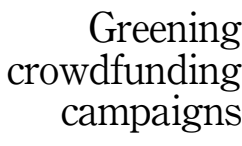

1399 
IJBM 39,7

environmental benefits derived from the realisation of their green projects (promotion), whereas they utilise negatively framed claims to highlight the removal of environmental harms (prevention). Existing evidence in the environmental domain leads us to anticipate the effectiveness of negative framing applied to green campaigns in the reward-based crowdfunding context. Thus, we formulate the following hypothesis:

H1. A negative goal frame for green projects has a greater positive effect on the probability of campaign success than does a positive goal frame.

The quantity and valence of green frames influence framing efficacy (Olsen et al., 2014), and both contribute to "green emphasis". The communication of explicitly green signals of a green product evidences the product's environmental characteristics and, thus, establishes a direct connection between the product and the environment (Defazio et al., 2020; Usrey et al., 2020).

In terms of quantity, environmental projects may employ multiple claims to communicate the environmental value of their initiatives. The increasing detail in green advertisements over time is a response to consumers' preference for full disclosure to comprehend sustainability dimensions (Cho, 2015; Engels et al., 2010). However, it also stems from the complexity of environmental problems and the organisers' need to differentiate green initiatives from competitors by communicating a green image (Leonidou and Leonidou, 2011). In terms of valence, research suggests that explicitly framing products as "green" encourages consumers to be more virtuous and engage in additional virtuous acts, such as donating to green causes (Spielman, 2020). According to Smith and Brower (2012), consumers scan for specific keywords that comprise their environmentally conscious schema when attempting to identify a product's environmental orientation. Consequently, including specific keywords related to a project's purpose in its title has a significant influence on the project's success (Yao et al., 2019).

Following these previous studies, we likewise hypothesise a positive effect of green emphasis on the probability of campaign success.

H2a. Green emphasis, measured as the presence of environmental keywords in a project's title, increases the probability of campaign success.

$H 2 b$. Green emphasis, measured as the number of environmental keywords in a project's description, increases the probability of campaign success.

Individuals react differently to environmental communications and, specifically, to the green advertising format (Bailey et al., 2016). Thus, when green entrepreneurs exert greater efforts to convince their audiences about the greenness of their operations and the products/services offered, they must take care to secure backers' trust by communicating project goals in a transparent and credible manner. For example, green entrepreneurs must promote the real impact of product-specific benefits, providing specific data and defining technical terms (Cho, 2015). Providing specific information positively affects individuals' opinions about the information presented, while nonspecific information increases uncertainty in decision-making (Kivetz and Simonson, 2000). In particular, Larrimore et al. (2011) demonstrate that quantitative information increases funding success and that concreteness, preciseness and interactivity boost the success of social campaigns. Presenting campaign aims in terms of quantitative content and numerical objectives may increase the perceived seriousness of the environmental project and the specificity of the environmental goal, effectively reducing uncertainty and building backers' confidence regarding the entrepreneur's ability and means to realise the project. Thus, we formulate the next hypothesis as follows:

H3. Providing quantitative information increases the probability of campaign success. 
Exploring the effects of goal frames is a more complicated endeavour than it is for other frames due to the manipulability of the message. This characteristic increases the susceptibility of goal frames to several linguistic and contextual variations (Levin and Gaeth, 1988; Krishnamurthy et al., 2001) and suggests the need to identify other moderating variables in the crowdfunding context to explore the persuasive impact of goal message framing (Kuo and Liu, 2014).

In particular, research indicates that sustainability attributes tend to be context specific (Devinney et al., 2006; Schuitema and de Groot, 2015; Prakash, 2002), and it highlights the moderating role of product type on consumers' reactions (Chen and Chang, 2013; Olsen et al., 2014). In the reward-based crowdfunding context, compared with lending and equity models, the consumer plays a central role as a financier of green innovation, and the investment decision is thereby similar to conventional purchasing decisions (Wang and Yang, 2019). Testa et al. (2020) and Nielsen and Binder (2020) pinpoint the important but scarcely explored role of different project categories on the success of reward-based campaigns. Each product proposed in a specific project category is characterised by specific values (egoistic, altruistic and biospheric) and attributes.

Following these previous studies, we examine the interaction between a project's category, message framing and green emphasis. In particular, we investigate the effects that different green project categories have on individuals' interpretations of the information provided and thus on the effectiveness of message framing (see Figure 1).

H4. The impact of message framing on the probability of campaign success depends on project categories.

H5. The impact of green emphasis on the probability of campaign success depends on project categories.

\section{Research methodology}

\subsection{Data collection}

To predict crowdfunding campaign success, we refer to the Indiegogo crowdfunding platform. Indiegogo, one of the world's most popular reward-based platforms, is featured in other studies on social and environmental projects (Hörish, 2018; Cumming et al., 2017). We further restrict our sample to projects in the category "Community projects - Environment".

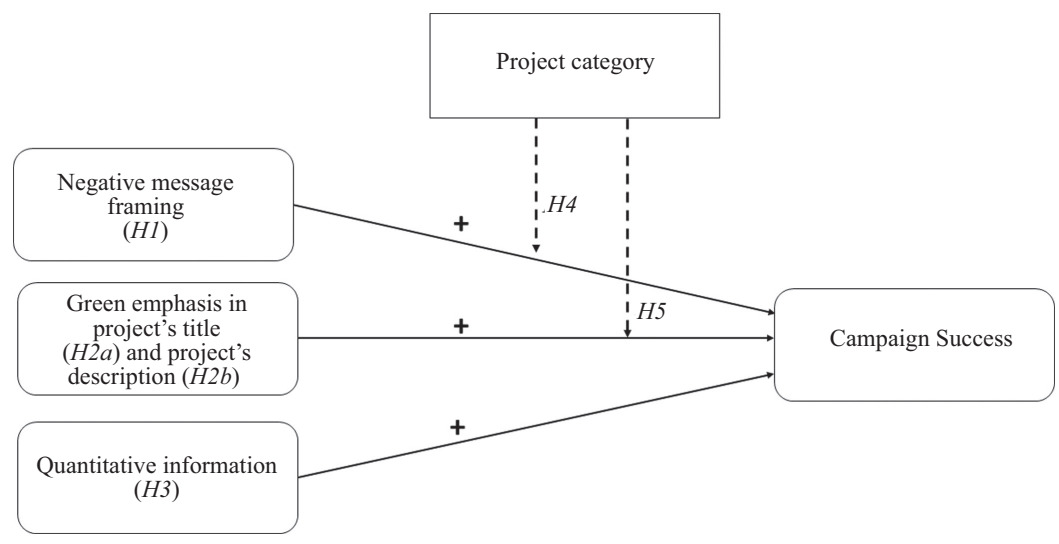

Figure 1. Conceptual framework 
IJBM

39,7

1402

The following reasons justify these choices: (1) Indiegogo.com is a generalist international platform that welcomes green projects, grouping them in dedicated sections on its web portal to allow backers to easily recognise their environmental orientation, and (2) The category "Community projects - Environment" includes projects that explicitly leverage both prosocial and pro-environmental behaviours. Another category available on Indiegogo for green projects is "Energy \& Green Tech", but we exclude it to avoid possible spurious effects that may derive when green product attributes converge with technological attributes.

We also exclude from the sample projects whose funding did not commence (because the amount raised is equal to $€ 0$ ) and projects for which the funding goal was below $€ 100$ (Mollick, 2014). Indiegogo adopts both "all or nothing" and "take it all" approaches. We select only projects with fixed goals, i.e. an "all or nothing" approach, which implies that entrepreneurs receive funders' contributions only if the campaign goal is reached or exceeded. The final sample consists of 86 projects launched and closed on the platform from 2015 to 2020. Finally, it is important to note that organisations are located worldwide and represent a sufficiently randomised sample as shown in Figure 2.

\subsection{Description of variables}

For each project, we collect the following variables. Table 1 provides the list and definitions of the outcome variable, together with the explanatory variables and controls employed in the subsequent analysis. Table 2 presents our sample descriptive statistics and $t$-test results performed to explore the main differences between successful and unsuccessful campaigns.

3.2.1 Dependent variable. Our dependent variable is the probability of campaign success, a dichotomous variable that takes the value of 1 if the campaign closes with success (i.e. it raised at least the target amount); otherwise, the value of the dependent variable is 0 . This measurement of success is often applied in crowdfunding studies (e.g. Kunz et al., 2017; Mitra and Gilbert, 2014; Mollick, 2014). In our sample, $43 \%$ of the campaigns closed successfully (i.e. they collected at least the target amount), and 39\% of the campaigns closed with overfunding (i.e. they collected more than the target amount). As an example, the most successful project in the sample is "WaterSeer", a mobile water solution promoted in the United States, which raised $€ 275,263$, or $19 \%$ higher than the amount requested. Another is "Mu thermal camera",

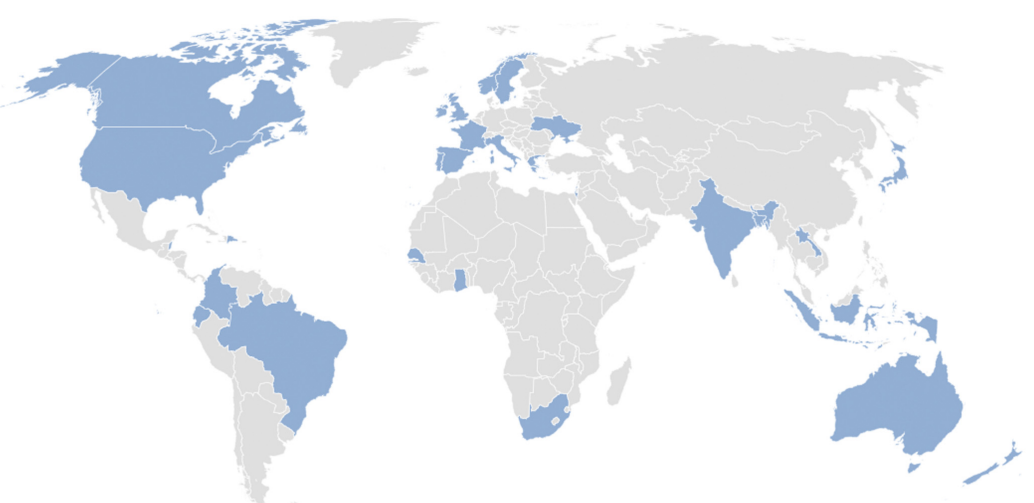

Figure 2.

Distribution of projects in the sample 


\section{Variable}

Description

Dependent variables

Success

Overfunding

Independent variables

Framing

Environmental_title

Environmental_words

S_Environmental_orientation

M_Environmental_orientation

L_Environmental_orientation

XL_Environmental orientation

Quantitative goal

Agri-food

Climate preservation

Clean energy

Control variables

Goal amount

Videos

Rewards

Updates

Europe
Dummy $=1$ if successful at closure

Dummy $=1$ if the import raised is higher compared with the import target

Dummy $=1$ if the project's aim has a negative frame; 0 for a positive frame Dummy $=1$ if the title of the campaign contains "environmental" keywords

Number of "environmental" keywords in the campaign description

Dummy $=1$ if the environmental words are in the first quartile (from 1 to 7 environmental words)

Dummy $=1$ if the environmental words are in the second quartile (from 8 to 13 environmental words)

Dummy $=1$ if the environmental words are in the third quartile (from 14 to 28 environmental words)

Dummy $=1$ if the environmental words are in the fourth quartile (from 29 to 93 environmental words)

Dummy $=1$ if the campaign aim is expressed in quantitative goals

Dummy $=1$ if the campaign is related to agricultural or food

Dummy $=1$ if the campaign is related to environmental and animal

conservation

Dummy $=1$ if the campaign is related to renewable energy and recycling

The amount of money required to fully finance the campaign

Number of videos in the campaign

Number of rewards proposed in the campaign

Number of updates in the campaign

Dummy $=1$ if the campaign is promoted in europe
Greening

crowdfunding

campaigns

1403

Table 1.

Variable definitions

a renewable energy electric utility, which raised $€ 230,244$, or $41 \%$ higher than the amount requested.

3.2.2 Independent variables. We analysed the independent variables - taken from the project description on each campaign's page - via an in-depth manual search for a predefined set of "environmental" keywords, including eco-innovation, eco-friendly, eco-effective, ecology, ecological, environmental, environmental-friendly, green, green innovation and renewable. Since a strict definition of "environmental" projects is lacking, we refer to the list of words adopted in previous studies (Butticè et al., 2019; Cumming et al., 2017; Vismara, 2019) and to "environmental" synonyms on WordReference.com. Next, two coders recruited from the undergraduate programme at the author's university developed the phases of project scrutinisation and quantification. The coders read the "Story" section of each project and identified the following: the negative or positive frame adopted in the definition of the campaign goal; the number of "environmental" keywords in each "Story"; and the presence of environmental" keywords in each project's title. In addition, the coders indicated whether or not the campaign goal was expressed in quantitative measures. Two different researchers validated the coders' observations for accuracy and coherence (Yin, 1983).

Negative or positive message framing is expressed by the variable Framing, which assumes the value of 1 when the campaign's aim is expressed with a negative frame and 0 when the campaign's aim is expressed with a positive frame. Examples of negatively framed messages include the following: "Cut greenhouse gas emissions by 121 tons per year" or "Here's the bottle that stops 1,000 plastic bottles from entering the ocean", while a 
IJBM

39,7

1404

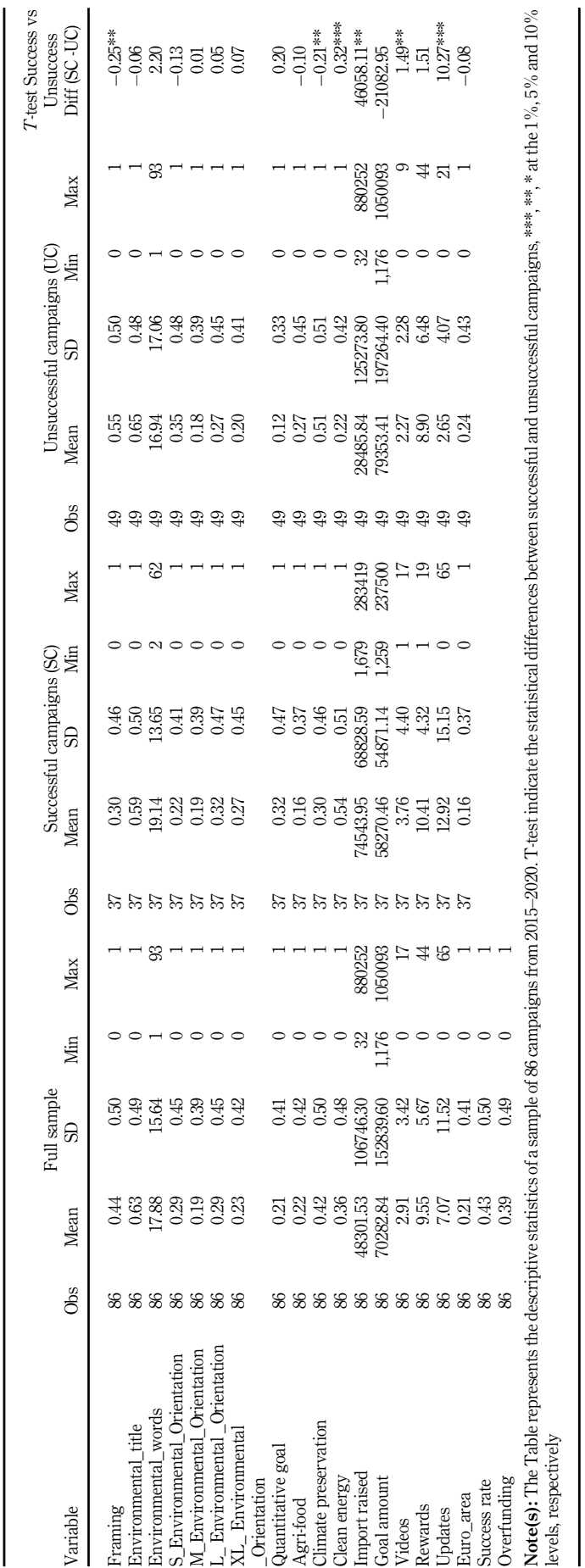

Table 2.

Descriptive statistics 
positively framed message states: "Every HomeBiogas system saves six tons C02 per year". In our sample, $44 \%$ of campaigns express their aim with a negative frame.

A project's green emphasis includes two variables: the number of "environmental" keywords (Environmental_words) in the project "Story" and a dummy variable (Environmental_title), which assumes a value of 1, as in Defazio et al. (2020), if the project's title features environmental keywords. On average, each project features 18 environmental keywords with a maximum of 93 keywords, and $63 \%$ of the campaigns present keywords in their project's title. To detect more granular information about Environmental_words, we examine the distribution of the number of words in our sample of campaigns by defining four quartiles that represent the magnitude of each project's environmental orientation. S_Environmental_Orientation is a dummy variable equal to 1 if the environmental orientation is in the first quartile (17 environmental words); otherwise, its value is 0 . M_Environmental_Orientation is a dummy variable equal to 1 if the environmental orientation is in the second quartile (8-13 environmental words); otherwise, its value is 0 . L_Environmental_Orientation is a dummy variable equal to 1 if the environmental orientation is in the third quartile (14-28 environmental words); otherwise, its value is 0 . XL_Environmental_Orientation is a dummy variable equal to 1 if the environmental orientation is in the fourth quartile (29-93 environmental words); otherwise, its value is 0 .

The variable Quantitative goal is a dummy variable with a value of 1 if the campaign's aim is expressed with a quantitative goal that refers to the product developed or, in the case of a campaign that has successfully concluded, project implementation. Some examples are as follows: "We will distribute 422 bike stations across the planet", or " $€ 5,000$ will be used to avoid pesticide use". Only $21 \%$ of the campaigns present a quantitative goal.

Finally, we carefully analyse the value propositions (i.e. product/service offering) formulated in the project descriptions and group projects according to the following categories: the Agri-food category includes projects or tools for sustainable agriculture and organic food production; the Climate preservation category includes projects combating climate change and promoting environmental and animal conservation; and the Clean energy category includes renewable energy projects or products deriving clean energy from recycled garbage. Since a single campaign could potentially be assigned to multiple categories, we labelled each campaign based on the project's primary focus. In our sample, $22 \%$ of projects promoted sustainable agriculture, $42 \%$ promoted climate preservation and $36 \%$ promoted clean energy projects.

3.2.3 Control variables. In addition to the independent variables of interest, several other variables may influence the probability of campaign success; thus, we must control for these variables. Some control variables refer to campaign structure while others refer to communication instruments.

The control variable Goal amount, which is the logarithm of the target amount in the campaign, serves as a proxy for campaign structure and controls for the size of the project (Butticè et al., 2019; Defazio et al., 2020; Mitra and Gilbert, 2014). In our sample, the average campaign goal is $€ 70,282$.

Previous studies reveal that the use of videos in project introductions (Greenberg et al., 2013; Kunz et al., 2017; Mollick, 2014), the number of updates published during the campaign and the number of rewards are associated with funding success (Cumming et al., 2017; Kuppuswamy and Bayus, 2017; Jiang et al., 2020; Moradi and Dass, 2019). Thus, we collect information on the number of videos available in the campaigns (Videos), the number of rewards (Rewards) and the number of project updates (Updates). The widespread use of these tools is confirmed in our sample where, on average, each project has three videos, nine rewards and seven updates.

Finally, we introduce a dummy geographic variable (Europe) to distinguish campaigns launched in Europe from those launched outside of Europe. 
IJBM

39,7

1406

Table 2 summarises the main differences between successful and unsuccessful campaigns. Successful campaigns raise more money than unsuccessful campaigns, but successful and unsuccessful campaigns exhibit no differences in their targets (Goal amount). In terms of message framing, a negative frame seems to impede success; in fact, only $30 \%$ of successful campaigns adopted a negative frame, but this proportion rises to $55 \%$ amongst unsuccessful campaigns. Successful projects are concentrated in the renewable energy sector $(54 \%)$, the climate change mitigation sectors $(30 \%)$ and the agri-food sector $(16 \%)$. More successful campaigns rely to a greater extent on videos to communicate their projects (on average, successful campaigns produce 3.76 videos, whereas unsuccessful campaigns produce an average of 2.27 videos), and they more frequently update information (successful campaigns publish an average of 12 updates, whereas unsuccessful campaigns publish an average of 2.65 updates).

\section{Model specification}

To detect the impact of message framing, green emphasis and the quantitative nature of a project's goal on the likelihood of a green campaign's success, we perform a probit regression. In the probit model, we estimate the probability that firm $i$ realises a successful campaign using the following equation:

$$
\begin{aligned}
\operatorname{Prob}_{\left(\text {Success }_{i}=1\right)=} & F\left(\alpha+\beta_{1}(\text { Framing })+\beta_{2}\left(\text { Environmental_orientation }_{i}\right.\right. \\
& +\beta_{3}(\text { Quantitative goal })_{i}+\beta_{4}(\text { Project category })_{i} \\
& +\beta_{5}(\text { Goal amount })+\beta_{6}(\text { Videos })+\beta_{7}(\text { Rewards })+\beta_{8}(\text { Updates }) \\
& \left.+\beta_{9}(\text { Geo area })+\beta_{10}(\text { Year })+\varepsilon_{i, k, t}\right)
\end{aligned}
$$

where Success represents the closing of a successful campaign for firm $i$ and $\alpha$ is a constant term. In the above equation, Framing is a dummy variable, which equals 1 if the project's aim has a negative frame and 0 if the project's aim has a positive frame. Environmental_orientation is a vector of campaign-specific variables (Environmental_title and Environmental_words), Quantitative goal is a dummy variable, which equals 1 if the project's goal is expressed in quantitative terms, and Project category is a vector of Climate preservation, Clean energy and Agri-food. We also control for goal amount, number of videos, rewards, updates and geographical and time fixed effects.

We run models with interaction between project categories (Climate preservation and Clean energy) and message framing, as well as green emphasis measured by the quartile of environmental words [1].

For each of our models, we verify the predictive power by the area under the ROC curve. Goodness of fit is assessed using Pearson's chi-square test, while the severity of multicollinearity is assessed through the variance inflation factor.

\section{Results}

We examine the effects of message framing, green emphasis and quantitative goals on the likelihood that a crowdfunding project will succeed in raising funds. Table 3 presents the results of our main analysis where the dependent variable represents the project's success (i.e. the campaign raised an amount of money equal to or greater than the target).

In Model I, the variables affecting the success of a green campaign are a positively framed message, a campaign goal expressed in quantitative terms and a project related to the clean energy category. The expression of the campaign's aim with a negatively framed message 


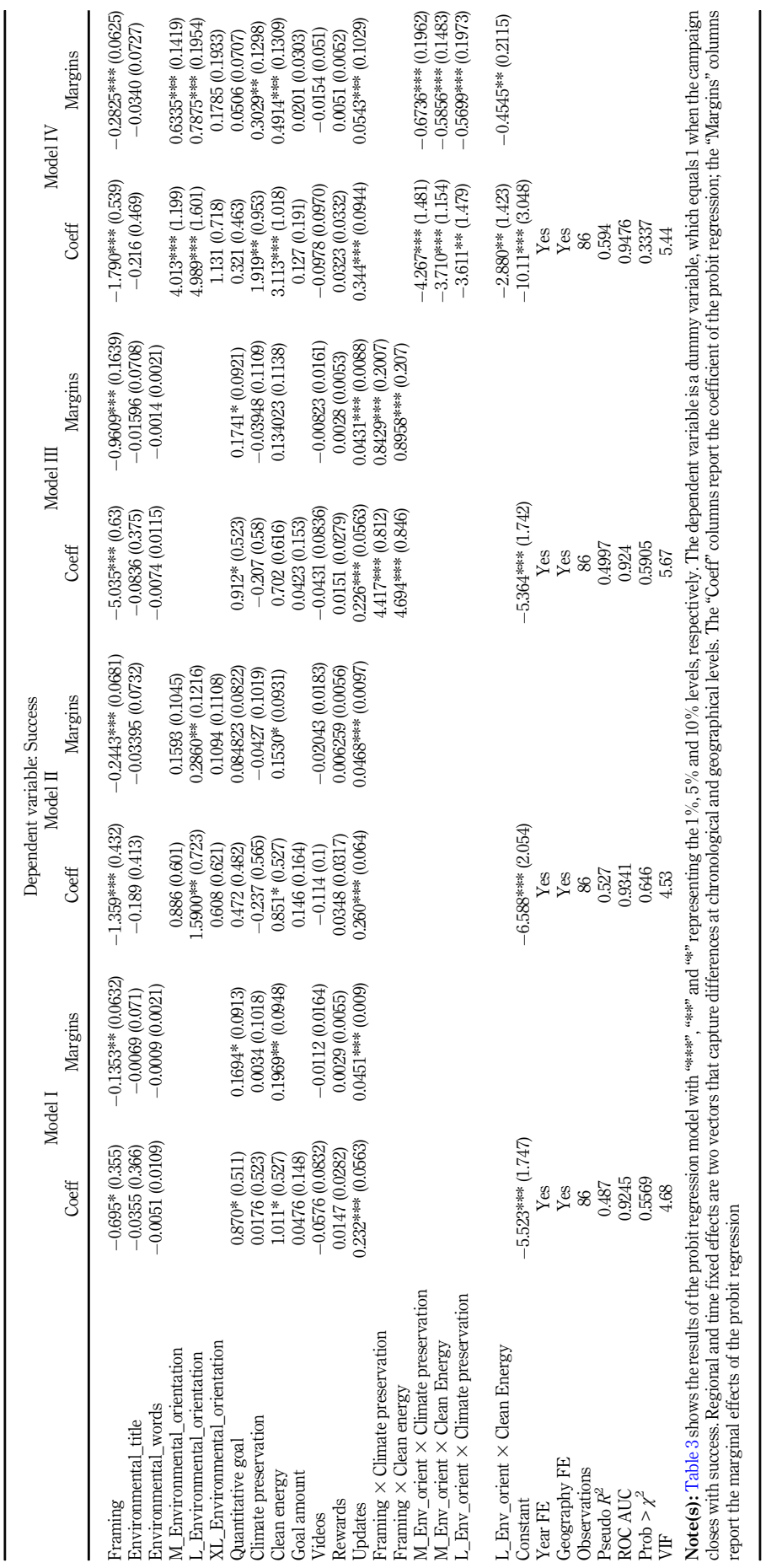

Greening crowdfunding campaigns

Table 3. Determinants of green campaigns success 
IJBM

39,7

1408

reduces the probability of the project's success by $13.53 \%$. Meanwhile, situating a project in the clean energy category leads to a probability of success that is $19.69 \%$ greater than that of projects situated in the agri-food category (see Margins column). Another important element affecting campaign success is the expression of a quantitative goal that refers to product development or project implementation. When a campaign expresses its goal in quantitative terms, the probability of its success is $16.94 \%$ greater than in the absence of quantitative information.

Consistent with previous studies (Jiang et al., 2020; Moradi and Dass, 2019), our model confirms that regular updates of campaign information produce greater success. The results of Model I do not confirm H1 ("A negative goal frame for green projects has a greater positive effect on the probability of campaign success than does a positive goal frame"), but they do confirm H3 ("Providing quantitative information increases the probability of campaign success").

$\mathrm{H} 2 \mathrm{a}$ and $\mathrm{H} 2 \mathrm{~b}$, which are related to green emphasis, require a more detailed investigation. In Model I, environmental words and title do not affect the probability of success (H2a). Considering the importance of the topic, however, we investigate the relevance of green emphasis in greater depth. Thus, we adopt a more granular approach in Model II, dividing the prevalence of environmental words into quartiles. Model II demonstrates that a green emphasis in the project description does affect campaign success (H2b). The presence of a significant number of environmental words (between 14 and 28 words - i.e. the third quartile of our distribution) increases the probability of success by $28 \%$ compared to descriptions that include a small number of environmental words (between 1 and 7 words - i.e. the first quartile). Consequently, we confirm $\mathrm{H} 2 \mathrm{~b}$ and state that a marked green emphasis engenders major campaign success, while neither few environmental words nor an exaggerated number of words enhances campaign success.

In Model III, we examine the relationship between project category and framing (H4). Specifically, we add to the analysis the interaction between framing and two project categories: Climate preservation and Clean Energy (agri-food is omitted). Negative message framing seems to increase the probability of project success significantly in the two sectors considered (by 84 and 89\%, respectively), whereas it impedes success amongst projects in the agri-food sector $(-96 \%)$. These results reveal that project category moderates the relationship between message framing and the probability of campaign success: a positive frame increases agri-food campaign success, while for clean energy and climate preservation projects, the negative frame is more effective than the positive one. This confirms our H4. Finally, in Model IV, we examine the relationship between project category and green emphasis measured as the quartile of words. We demonstrate that even if, as discussed before, green emphasis increases the probability of campaign success, this effect is more prominent for agricultural projects than for climate or energy projects (see Margins column in Model IV), confirming the moderating role of project category in this relationship (H5).

\section{Robustness tests}

To verify the robustness of our results, we conduct the analysis again while considering an alternative indicator of success. We create the variable Overfunded as the ratio between the funds raised and the target amount. The variable is equal to 1 if the amount raised is greater than the target amount; otherwise, its value is 0 (we exclude the cases where the funds raised perfectly equal the target amount) [2].

Specifically, in Models IV-VII of Table 4, the dependent variable is the probability that a campaign will achieve overfunding. In these models, negative framing, an increased green emphasis - i.e. a greater use of environmental words (from 29 to 93 words), and quantitative goals (even if the latter appear only in Model VII) affect the odds of overfunding. Our results 


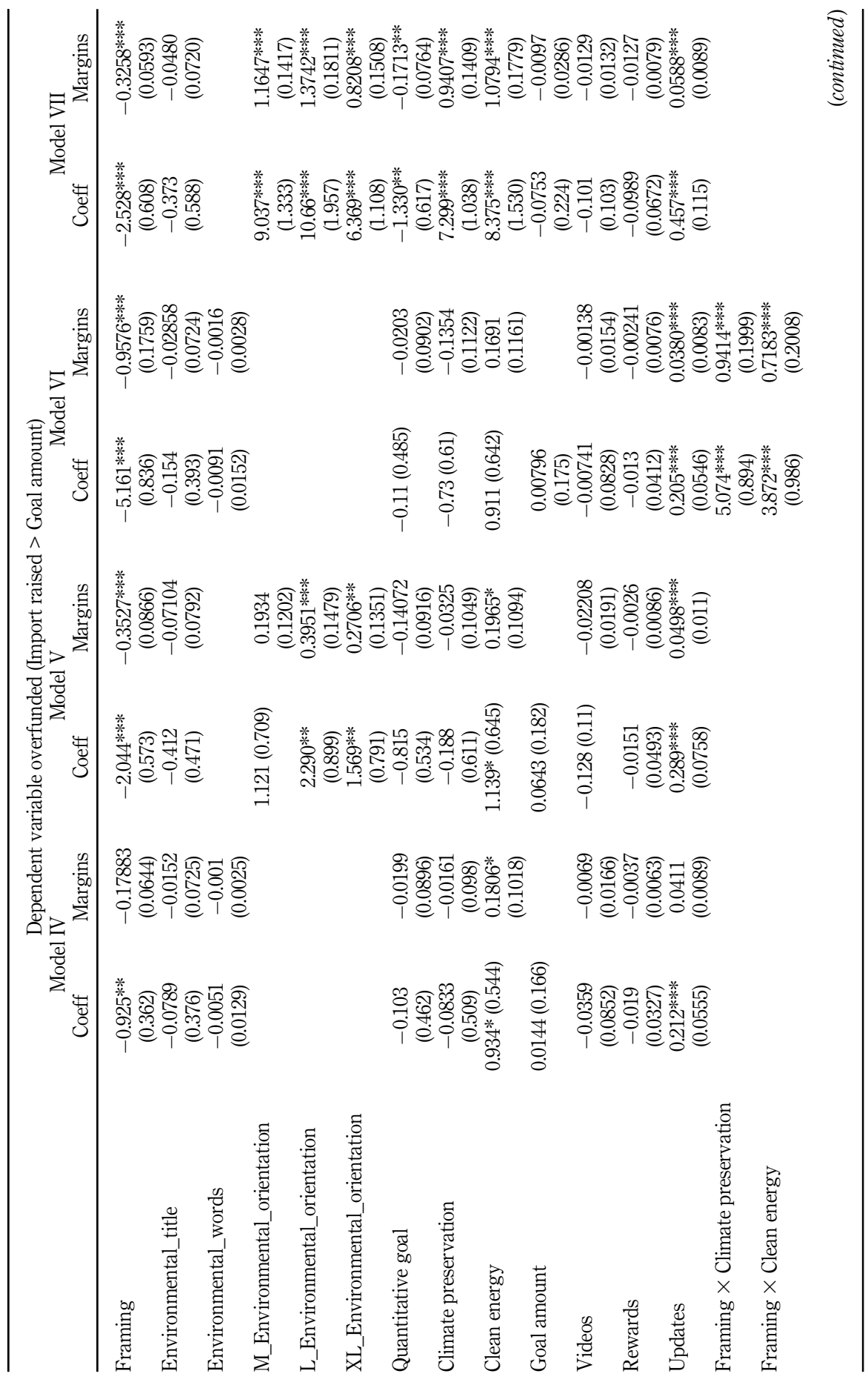

Greening crowdfunding campaigns

1409

Table 4

Determinants of overfunding 
IJBM
39,7

1410

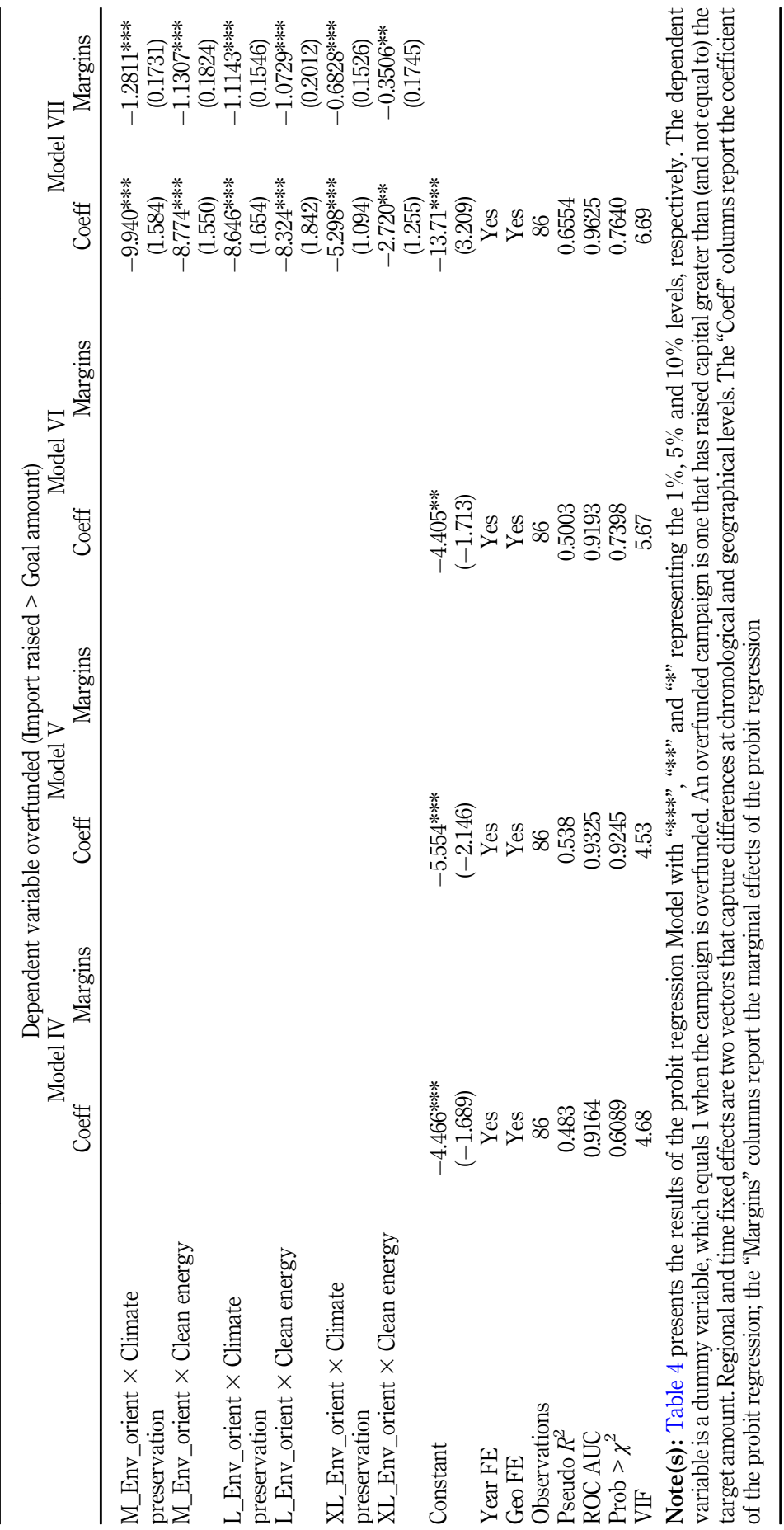

Table 4. 
about message framing and green emphasis and their interaction with project category are thus robust to the inclusion of an alternative dependent variable representing success.

\section{Discussion and conclusions}

In recent years, researchers and activists have exhibited a growing interest in studying ways to promote the funding of green initiatives and pro-environmental behaviour. Within this context, most researchers and practitioners have focused on identifying the elements that increase the effectiveness of environmental-related messages. The current study aims to explore the influence of message framing, green emphasis and quantitative information on the probability of green crowdfunding campaigns' success. To achieve their funding goals, entrepreneurs leading crowdfunding campaigns can choose what information to disclose, how to disclose it and which tools to adopt to improve the information's credibility.

First, our results demonstrate that a project's category moderates the relationship between message frame and the odds of campaign success. Specifically, agri-food campaigns benefit from positively framed messages, while negatively framed messages are more effective for climate preservation and clean energy campaigns. The majority of agri-food projects in the sample aim to assist disadvantaged individuals through the implementation of agricultural projects. In these campaigns, pro-social aims and pro-environmental aims are combined, while for climate preservation and clean energy projects, environmental aims command the primary focus. According to the product values categorisation proposed by Nielsen and Binder (2020), agri-food campaigns focus on both the benefits of a given product in terms of its social utility (e.g. good labour conditions, the health of the local economy) and the benefits of the product in terms of its environmental impact; meanwhile, climate preservation and clean energy projects focus exclusively on environmental utility (e.g. reduction of carbon emissions). This difference suggests that positively framed messages are generally more effective than negatively framed messages when an entrepreneur combines both pro-social and pro-environmental aims in a single project; on the other hand, negatively framed messages are preferable for campaigns that focus mainly on pro-environmental goals. These findings solidify the results of previous studies, which have found that negative framing is more effective in promoting pro-environmental products (e.g. Amatulli et al., 2019; Borin et al., 2011; Grankvist et al., 2004; Karpinska-Krakowiak et al., 2020). In the crowdfunding context where backers have limited time to support the campaign and an increased risk perception due to the difficulties involved in evaluating campaign information, negative goal messaging may be more effective than positive goal messaging for environmental products because negative messaging generates negative emotions (Chang and $\mathrm{Wu}, 2015)$, such as fear and anger, and thus increases the urgency to mobilise money to finance the proposed project. The effectiveness of positive frames for agri-food projects is consistent with results in the microlending context reported by Allison et al. (2015), which show an advantage for positively framed messages in supporting pro-social projects.

Original in our work is the application of the previous literature about framing to a new context, i.e. green crowdfunding campaigns. Despite the wide use of digital financial instruments by multiple organisations in this field, research that combines framing and the environmental literature is lacking (Jacobson et al., 2019), as is an application of framing theory to the entrepreneurial setting (Pan et al., 2020). Thus, our work expands upon both the crowdfunding literature about green campaign success determinants (Butticè et al., 2019; Cumming et al., 2017; Kim and Hall, 2021; Hörisch, 2018) and the literature about the importance of language in promoting new entrepreneurial projects and their funding activities (Kaminski and Hopp, 2020; Koh et al., 2020; Parhankangas and Renko, 2017).

Second, our results indicate that project category moderates the relationship between green emphasis and campaign success. A significant number of environmental claims in a

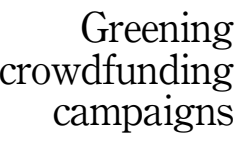

1411 
IJBM 39,7

1412

campaign's text positively affects the likelihood of the campaign's success and the possibility that it will achieve overfunding, but this relationship changes amongst different project categories. Partially supporting Defazio et al.'s (2020) study demonstrating that a highly emphasised pro-social orientation is associated with a lower probability of campaign success, our study of green projects finds that a too marked green emphasis does negatively impact the success of climate preservation and clean energy campaigns, but it positively effects the success of agri-food projects. An exaggeration of environmental claims in projects characterised by a strong pro-environmental orientation may be perceived as greenwashing (Parguel et al., 2011, 2015), increasing backers' scepticism. Since greenwashing includes dishonest efforts to increase the importance of irrelevant facts, consumers are now more sceptical of purportedly green and social messages (do Paço et al., 2019), especially in the digital context where no subjects certifies published information. Our findings are, however, good news for agri-food entrepreneurs who can seize competitive advantages by presenting themselves as greener than competing projects. Because our results suggest that backers perceive pro-social and pro-environmental entrepreneurial projects differently, we follow Calic and Mosakowski (2016) and Nielsen and Binder (2020), who distinguish between social and environmental-oriented campaigns and identified different pledging behaviour, and assert that social and environmental entrepreneurs must develop different message framing and green emphasis strategies to increase their funding chances.

Importantly, however, backers' evaluations of environmental claims are not focused on a project's title but on its content, which means that backers pay careful attention to the details of a proposed idea and its description. This confirms previous evidence regarding consumers' preference for the disclosure of detailed and comprehensive information to facilitate their understanding of projects' sustainability dimensions (Cho, 2015; Engels et al., 2010).

Third, even after they have provided comprehensible information about a project's environmental and/or social orientation, entrepreneurs face yet another challenge: backers must perceive the information provided as credible. In this regard, the expression of campaign goals via quantitative information increases the probability of campaign success. Previous studies have demonstrated that one of the most significant barriers to the adoption of pro-environmental behaviour is backers' difficulty in understanding the benefits generated (Gifford, 2011; Kollmuss and Agyeman, 2002). Simply put, backers require information to make informed choices, and this information must be comprehensible, concrete and precise while promoting the real impact of product-specific benefits (Larrimore et al., 2011). Consistent with the notion that understanding the benefits of an action facilitates the action (Lagomarsino et al., 2020), the identification of a campaign goal with quantitative information increases the concreteness of the campaign and thus promotes campaign success. Because backers must rely not on verified information but on the information the entrepreneur chooses to report on the campaign page, ample room does remain for the misrepresentation of product features and performance. However, the indication of a quantitative goal mitigates the risk of performance opacity perceived by backers, especially in crowdfunding campaigns (Belavina et al., 2020).

From a practical perspective, our findings imply that strategically applying framing messages and communication maximises backers' responses to green crowdfunding projects and thus maximises project success. These findings reveal how green entrepreneurs should think about information disclosure strategies and environmental claims. Based on our findings, green marketing in crowdfunding campaigns could be viewed as a subset of the voluntary information disclosure strategies available to entrepreneurs to promote their products to potential campaign supporters and future customers. First, the linkage between message framing and project category in this study 
suggests that green entrepreneurs should tailor their marketing and communication strategies to the project type proposed. In particular, clean energy and climate change projects may benefit the most from the adoption of crowdfunding since they fall into the project category with the greatest campaign success. Second, firms should seek to increase the credibility of disclosed information by presenting their goals in quantitative terms and highlighting their projects' environmental orientation. Visual cues and eco-labels may present other useful vehicles for strengthening the effectiveness of a project's environmental orientation.

Considering the lack of dialogue between those seeking funding for their projects and financial contributors/investors searching for investable projects, the practical implication of our findings may be extended to other contexts to improve the effectiveness of communication strategies in attracting financial supporters and helping investors make better decision. Projects such as those launched by the Global Green Council (e.g. the Green Lending Principles) or the European Investment Project Portal (EIPP), which is a publicly available web portal of investment projects acting as a platform to promote projects to potential investors worldwide, are among those that could benefit from our findings. Therefore, our findings suggest important measures to increase the awareness of green finance issues amongst key players, which, in turn, constitutes a crucial element for the implementation of the European Fund for Strategic Investments (EFSI).

Despite its contributions, this study, like all research, entails some limitations. First, when considering the generalisability of our results, one must keep in mind that this study derives data from a single crowdfunding platform. New platforms and new kinds of projects are constantly evolving in the crowdfunding market. Future studies could enlarge the number of projects in the sample, the number of observed platforms and the types of crowdfunding models investigated (e.g. equity-based and lending-based models). Second, the project categories investigated may reflect different product attributes. As Testa et al. (2020) reveal, some attributes of sustainability-oriented product/services pursued within crowdfunding campaigns are critical for increasing the odds of campaign success. Future studies could delve deeply into these green product attributes to understand which of them is the most effective and how the combination of technology and green attributes can enhance green crowdfunding campaign performance. Moreover, since each project is characterised by a different graphical layout and different communication tools, a fruitful investigation could explore the interaction between the visual cues and text campaigns employ. Finally, future research might further extend our work by considering other types of framing in crowdfunding campaigns. About this last point, the empirical method employed in this study is limited in its ability to isolate the effect of alternatively framed pitches for the same campaign on backers' intentions. Future studies could combine empirical and experimental methodology to observe how different campaign frames affect respondents' decision. We leave this issue open for future research.

\section{Notes}

1. In this study, we are not able to assess the moderating effect of project category on the quantitative goal due to the absence of climate preservation projects declaring quantitative goals.

2. To assess the robustness of our results, we run our models with an alternative measure of overfunding. We calculate the variable Overfunded_restricted as follows: Based on the distribution of the variable Overfunded for successful projects, we select the value of the first quartile that is equal to $1 \%$. The variable Overfunded_restricted equals 1 if the funds raised are $1 \%$ higher than the target amount; otherwise, its value is 0 . Following this definition, $33 \%$ of our campaigns are overfunded. Our results are robust to the inclusion of this alternative dependent variable representing overfunding. Results are available upon request to the authors.

\section{Greening crowdfunding campaigns}


IJBM

39,7

\section{References}

Allison, T.H., Davis, B.C., Short, J.C. and Webb, J.W. (2015), "Crowdfunding in a prosocial microlending environment: examining the role of intrinsic versus extrinsic cues", Entrepreneurship: Theory and Practice, Vol. 39 No. 1, pp. 53-73.

Amatulli, C., De Angelis, M., Peluso, A.M., Soscia, I. and Guido, G. (2019), "The effect of negative message framing on green consumption: an investigation of the role of shame", Journal of Business Ethics, Vol. 157 No. 4, pp. 1111-1132.

Avineri, E. and Owen, W.E. (2013), "Applying valence framing to enhance the effect of information on transport-related carbon dioxide emissions", Transportation Research Part A: Policy and Practice, Vol. 48, pp. 31-38.

Bailey, A.A., Mishra, A. and Tiamiyu, M.F. (2016), "Green advertising receptivity: an initial scale development process", Journal of Marketing Communications, Vol. 22 No. 3, pp. 327-345.

Belavina, E., Marinesi, S. and Tsoukalas, G. (2020), "Rethinking crowdfunding platform design: mechanisms to deter misconduct and improve efficiency", Management Science, Vol. 66 No. 11, pp. 4980-4997.

Belleflamme, P., Lambert, T. and Schwienbacher, A. (2014), "Crowdfunding: tapping the right crowd", Journal of Business Venturing, Vol. 29 No. 5, pp. 585-609.

Belz, F.M. and Binder, J.K. (2017), "Sustainable entrepreneurship: a convergent process model", Business Strategy and the Environment, Vol. 26 No. 1, pp. 1-17.

Bilandzic, H., Kalch, A. and Soentgen, J. (2017), "Effects of goal framing and emotions on perceived threat and willingness to sacrifice for climate change", Science Communication, Vol. 39 No. 4, pp. 466-491.

Borin, N., Cerf, D.C. and Krishnan, R. (2011), "Consumer effects of environmental impact in product labeling”, Journal of Consumer Marketing, Vol. 28 No. 1, pp. 76-86.

Butticè, V., Colombo, M.G., Fumagalli, E. and Orsenigo, C. (2019), "Green oriented crowdfunding campaigns: their characteristics and diffusion in different institutional settings", Technological Forecasting and Social Change, Vol. 141, pp. 85-97.

Calic, G. and Mosakowski, E. (2016), "Kicking off social entrepreneurship: how a sustainability orientation influences crowdfunding success", Journal of Management Studies, Vol. 53 No. 5, pp. 738-767.

Castellacci, F. and Lie, C.M. (2017), "A taxonomy of green innovators: empirical evidence from South Korea”, Journal of Cleaner Production, Vol. 143, pp. 1036-1047.

Chang, C.T. and Lee, Y.K. (2009), "Framing charity advertising: influences of message framing, image valence, and temporal framing on a charitable appeal", Journal of Applied Social Psychology, Vol. 39 No. 12, pp. 2910-2935.

Chang, M.C. and Wu, C.C. (2015), "The effect of message framing on pro-environmental behavior intentions: an information processing view", British Food Journal, Vol. 117 No. 1, pp. 339-357.

Chang, H., Zhang, L. and Xie, G.X. (2015), "Message framing in green advertising: the effect of construal level and consumer environmental concern", International Journal of Advertising, Vol. 34 No. 1, pp. 158-176.

Chen, Y.S. and Chang, C.H. (2013), "Greenwash and green trust: the mediation effects of green consumer confusion and green perceived risk", Journal of Business Ethics, Vol. 114 No. 3, pp. 489-500.

Cho, Y.N. (2015), "Different shades of green consciousness: the interplay of sustainability labeling and environmental impact on product evaluations", Journal of Business Ethics, Vol. 128 No. 1, pp. 73-82.

Chuah, S.H. and Devlin, J. (2011), "Behavioural economics and financial services marketing: a review", International Journal of Bank Marketing, Vol. 29 No. 6, pp. 456-469. 
Cosma, S., Grasso, A.G., Pattarin, F. and Pedrazzoli, A. (2021), "Platforms' partner networks: the missing link in crowdfunding performance", European Journal of Innovation Management. doi: 10.1108/EJIM-06-2020-0230.

Cumming, D.J., Leboeuf, G. and Schwienbacher, A. (2017), "Crowdfunding cleantech", Energy Economics, Vol. 65, pp. 292-303.

Das, E., Kerkhof, P. and Kuiper, J. (2008), "Improving the effectiveness of fundraising messages: the impact of charity goal attainment, message framing, and evidence on persuasion", Journal of Applied Communication Research, Vol. 36 No. 2, pp. 161-175.

Defazio, D., Franzoni, C. and Rossi-Lamastra, C. (2020), "How pro-social framing affects the success of crowdfunding projects: the role of emphasis and information crowdedness", Journal of Business Ethics. doi: 10.1007/s10551-020-04428-1.

Devinney, T.M., Auger, P., Eckhardt, G. and Birtchnell, T. (2006), "The other CSR: making consumers socially responsible", Stanford Social Innovation Review, Vol. 4 No. 3, pp. 30-37.

Dobson, D.S. and Poels, K. (2020), "Combined framing effects on attitudes and behavioral intentions toward mortgage advertisements", International Journal of Bank Marketing, Vol. 38 No. 4, pp. 961-986.

do Paço, A., Shiel, C. and Alves, H. (2019), "A new model for testing green consumer behaviour", Journal of Cleaner Production, Vol. 207, pp. 998-1006.

Druckman, J.N. (2001), “The implications of framing effects for citizen competence”, Political Behavior, Vol. 23 No. 3, pp. 225-256.

Engels, S.V., Hansmann, R. and Scholz, R.W. (2010), "Toward a sustainability label for food products: an analysis of experts' and consumers' acceptance", Ecology of Food and Nutrition, Vol. 49 No. 1, pp. 30-60.

European Commission (2018), “Action plan financing sustainable growth, COM/2018/097 final”, available at: https:/eur-lex.europa.eu/legal-content/EN/TXT/?uri=CELEX\%3A52018DC0097.

European Commission (2019), "The European green deal, COM(2019) 640 final", available at: https:// eur-lex.europa.eu/resource.html?uri=cellar:b828d165-1c22-11ea-8c1f-01aa75ed71a1.0002.02/ DOC_1\&format=PDF.

Gerber, E.M. and Hui, J. (2013), "Crowdfunding: motivations and deterrents for participation", ACM Transactions on Computer-Human Interaction, Vol. 20 No. 6, p. 32.

Gifford, R. (2011), "The dragons of inaction: psychological barriers that limit climate change mitigation and adaptation", American Psychologist, Vol. 66 No. 4, pp. 290-302.

Grankvist, G., Dahlstrand, U. and Biel, A. (2004), "The impact of environmental labelling on consumer preference: negative vs. Positive labels", Journal of Consumer Policy, Vol. 27 No. 2, pp. 213-230.

Greenberg, M.D., Pardo, B., Hariharan, K. and Gerber, E. (2013), "Crowdfunding support tools: predicting success and failure", Conference on Human Factors in Computing Systems Proceedings, 2013-April, pp. 1815-1820.

Hauff, J.C., Carlander, A., Gamble, A., Gärling, T. and Holmen, M. (2014), "Storytelling as a means to increase consumers' processing of financial information", International Journal of Bank Marketing, Vol. 32 No. 6, pp. 494-514.

Hörisch, J. (2018), “Think big' or 'small is beautiful'? An empirical analysis of characteristics and determinants of success of sustainable crowdfunding projects", International Journal of Entrepreneurial Venturing, Vol. 10, pp. 111-129.

Jacobson, S.K., Morales, N.A., Chen, B., Soodeen, R., Moulton, M.P. and Jain, E. (2019), "Love or Loss: effective message framing to promote environmental conservation", Applied Environmental Education and Communication, Vol. 18 No. 3, pp. 252-265.

Jiang, C., Han, R., Xu, Q. and Liu, Y. (2020), “The impact of soft information extracted from descriptive text on crowdfunding performance", Electronic Commerce Research and Applications, Vol. 43, doi: $10.1016 /$ j.elerap.2020.101002.

\section{Greening crowdfunding campaigns}


IJBM

39,7

1416

Kahneman, D. and Tversky, A. (1979), "Kahneman and Tversky (1979) - prospect theory - an analysis of decision under Risk.pdf", Econometrica.

Kaminski, J.C. and Hopp, C. (2020), "Predicting outcomes in crowdfunding campaigns with textual, visual, and linguistic signals", Small Business Economics, Vol. 55 No. 3, pp. 627-649.

Karimi Takalo, S., Sayyadi Tooranloo, H. and Shahabaldini parizi, Z. (2021), "Green innovation: a systematic literature review”, Journal of Cleaner Production. doi: 10.1016/j.jclepro.2020.122474.

Karpinska-Krakowiak, M., Skowron, L. and Ivanov, L. (2020), "I will start saving natural resources, only when you show me the planet as a person in danger': the effects of message framing and anthropomorphism on pro-environmental behaviors that are viewed as effortful", Sustainability (Switzerland), Vol. 12 No. 14, p. 5524.

Kim, M.J. and Hall, C.M. (2021), "Do value-attitude-behavior and personality affect sustainability crowdfunding initiatives?”, Journal of Environmental Management, Vol. 280, doi: 10.1016/j. jenvman.2020.111827.

Kivetz, R. and Simonson, I. (2000), "The effects of incomplete information on consumer choice", Journal of Marketing Research, Vol. 37 No. 4, pp. 427-448.

Koh, Y., Lee, M., Kim, J. and Yang, Y. (2020), "Successful restaurant crowdfunding: the role of linguistic style", International Journal of Contemporary Hospitality Management, Vol. 32 No. 10, pp. 3051-3066.

Kollmuss, A. and Agyeman, J. (2002), "Mind the Gap: why do people act environmentally and what are the barriers to pro-environmental behavior?", Environmental Education Research, Vol. 8 No. 3, pp. 239-260.

Krishnamurthy, P., Carter, P. and Blair, E. (2001), "Attribute framing and goal framing effects in health decisions", Organizational Behavior and Human Decision Processes, Vol. 85 No. 2, pp. 382-399.

Kunz, M.M., Bretschneider, U., Erler, M. and Leimeister, J.M. (2017), “An empirical investigation of signaling in reward-based crowdfunding", Electronic Commerce Research, Vol. 17 No. 3, pp. $425-461$.

Kuo, Y.F. and Liu, L. Te. (2014), "The effects of framing and cause-related marketing on crowdfunding sponsors' intentions: a model development", 12th International Conference on Advances in Mobile Computing and Multimedia, MoMM 2014, pp. 439-443.

Kuppuswamy, V. and Bayus, B.L. (2017), “Does my contribution to your crowdfunding project matter?”, Journal of Business Venturing, Vol. 32 No. 1, pp. 72-89.

Lagomarsino, M., Lemarié, L. and Puntiroli, M. (2020), "When saving the planet is worth more than avoiding destructionThe importance of message framing when speaking to egoistic individuals", Journal of Business Research, Vol. 118, pp. 162-176.

Larrimore, L., Jiang, L., Larrimore, J., Markowitz, D. and Gorski, S. (2011), "Peer to peer lending: the relationship between language features, trustworthiness, and persuasion success", Journal of Applied Communication Research, Vol. 39 No. 1, pp. 19-37.

Leong, K. (2018), "FinTech (financial technology): what is it and how to use technologies to create business value in fintech way?", International Journal of Innovation, Management and Technology, Vol. 37 No. 4, pp. 74-78.

Leonidou, C.N. and Leonidou, L.C. (2011), "Research into environmental marketing/management: a bibliographic analysis", European Journal of Marketing, Vol. 45 No. 1, pp. 68-103.

Levin, I.P. and Gaeth, G.J. (1988), "How consumers are affected by the framing of attribute information before and after consuming the product", Journal of Consumer Research, Vol. 15 No. 3, p. 374.

Levin, I.P., Schneider, S.L. and Gaeth, G.J. (1998), "All frames are not created equal: a typology and critical analysis of framing effects", Organizational Behavior and Human Decision Processes, Vol. 76 No. 2, pp. 149-188. 
Maniatis, P. (2016), "Investigating factors influencing consumer decision-making while choosing green products", Journal of Cleaner Production, Vol. 132, pp. 215-228.

Manning, S. and Bejarano, T.A. (2017), "Convincing the crowd: entrepreneurial storytelling in crowdfunding campaigns", Strategic Organization, Vol. 15 No. 2, pp. 194-219.

Mason, C., Botelho, T. and Harrison, R. (2019), "The changing nature of angel investing: some research implications", Venture Capital, Vol. 21 Nos 2-3, pp. 177-194.

Messeni Petruzzelli, A., Natalicchio, A., Panniello, U. and Roma, P. (2019), "Understanding the crowdfunding phenomenon and its implications for sustainability", Technological Forecasting and Social Change, Vol. 141, pp. 138-148.

Mitra, T. and Gilbert, E. (2014), "The language that gets people to give: phrases that predict success on kickstarter", Proceedings of the ACM Conference on Computer Supported Cooperative Work, CSCW, pp. 49-61.

Mollick, E. (2014), "The dynamics of crowdfunding: an exploratory study", Journal of Business Venturing, Vol. 29 No. 1, pp. 1-16.

Moradi, M. and Dass, M. (2019), "An investigation into the effects of message framing on crowdfunding funding level", Journal of Electronic Commerce Research, Vol. 20 No. 4, pp. 238-254.

Nabi, R.L., Gustafson, A. and Jensen, R. (2018), "Framing climate change: exploring the role of emotion in generating advocacy behavior", Science Communication, Vol. 40 No. 4, pp. 442-468.

Nan, X., Daily, K. and Qin, Y. (2018), "Relative persuasiveness of gain-vs. loss-framed messages: a review of theoretical perspectives and developing an integrative framework", Review of Communication, Vol. 18 No. 4, pp. 370-390.

Nielsen, K.R. and Binder, J.K. (2020), "I Am what I pledge: the importance of value alignment for mobilizing backers in reward-based crowdfunding”, Entrepreneurship: Theory and Practice. doi: 10.1177/1042258720929888.

Olsen, M.C., Slotegraaf, R.J. and Chandukala, S.R. (2014), "Green claims and message frames: how green new products change brand attitude", Journal of Marketing, Vol. 78 No. 5, pp. 119-137.

Pan, L., Li, X., Chen, J. and Chen, T. (2020), "Sounds novel or familiar? Entrepreneurs' framing strategy in the venture capital market", Journal of Business Venturing, Vol. 35 No. 2, doi: 10.1016/j. jbusvent.2019.02.003.

Parguel, B., Benoit-Moreau, F. and Larceneux, F. (2011), "How sustainability ratings might deter 'greenwashing': a closer look at ethical corporate communication", Journal of Business Ethics, Vol. 102 No. 1, pp. 15-28.

Parguel, B., Benoit-Moreau, F. and Russell, C.A. (2015), "Can evoking nature in advertising mislead consumers? The power of 'executional greenwashing", International Journal of Advertising, Vol. 34 No. 1, pp. 107-134.

Parhankangas, A. and Renko, M. (2017), "Linguistic style and crowdfunding success among social and commercial entrepreneurs", Journal of Business Venturing, Vol. 32 No. 2, pp. 215-236.

Prakash, A. (2002), "Green marketing, public policy and managerial strategies”, Business Strategy and the Environment, Vol. 11 No. 5, pp. 285-297.

Ropret Homar, A. and Knežević Cvelbar, L. (2021), "The effects of framing on environmental decisions: a systematic literature review”, Ecological Economics. doi: 10.1016/j.ecol.

Schuitema, G. and de Groot, J.I.M. (2015), "Green consumerism: the influence of product attributes and values on purchasing intentions", Journal of Consumer Behaviour, Vol. 14 No. 1, pp. 57-69.

Schwienbacher, A. and Larralde, B. (2012), "Crowdfunding of small entrepreneurial ventures", SSRN Electronic Journal. doi: 10.2139/ssrn.1699183.

Smith, K.T. and Brower, T.R. (2012), "Longitudinal study of green marketing strategies that influence Millennials", Journal of Strategic Marketing, Vol. 20 No. 6, pp. 535-551. 
IJBM 39,7

Song, C., Wang, T. and Hu, M.Y. (2019), "Referral reward programs with scarcity messages on bank credit card adoption", International Journal of Bank Marketing, Vol. 37 No. 2, pp. 531-544.

Spielmann, N. (2020), "Green is the new white: how virtue motivates green product purchase", Journal of Business Ethics. doi: 10.1007/s10551-020-04493-6.

Testa, S., Nielsen, K.R., Bogers, M. and Cincotti, S. (2019), "The role of crowdfunding in moving towards a sustainable society", Technological Forecasting and Social Change, North-Holland, Vol. 141, pp. 66-73.

Testa, S., Roma, P., Vasi, M. and Cincotti, S. (2020), "Crowdfunding as a tool to support sustainabilityoriented initiatives: preliminary insights into the role of product/service attributes", Business Strategy and the Environment, Vol. 29 No. 2, pp. 530-546.

Tversky, A. and Kahneman, D. (1981), "The framing of decisions and the psychology of choice", Science, Vol. 211 No. 4481, pp. 453-458.

Usrey, B., Palihawadana, D., Saridakis, C. and Theotokis, A. (2020), "How downplaying product greenness affects performance evaluations: examining the effects of implicit and explicit green signals in advertising", Journal of Advertising, Vol. 49 No. 2, pp. 125-140.

Van de Velde, L., Verbeke, W., Popp, M. and van Huylenbroeck, G. (2010), "The importance of message framing for providing information about sustainability and environmental aspects of energy", Energy Policy, Vol. 38 No. 10, pp. 5541-5549.

Vismara, S. (2019), "Sustainability in equity crowdfunding", Technological Forecasting and Social Change, Vol. 141, pp. 98-106.

Wakeford, J.J., Gebreeyesus, M., Ginbo, T., Yimer, K., Manzambi, O., Okereke, C., Black, M. and Mulugetta, Y. (2017), "Innovation for green industrialisation: an empirical assessment of innovation in Ethiopia's cement, leather and textile sectors", Journal of Cleaner Production, Vol. 166, pp. 503-511.

Wang, Z. and Yang, X. (2019), "Understanding backers' funding intention in reward crowdfunding: an elaboration likelihood perspective”, Technology in Society, Vol. 58, doi: 10.1016/j.techsoc.2019. 101149 .

Wehnert, P., Baccarella, C.V. and Beckmann, M. (2019), "In crowdfunding we trust? Investigating crowdfunding success as a signal for enhancing trust in sustainable product features", Technological Forecasting and Social Change, Vol. 141, pp. 128-137.

White, K., Macdonnell, R. and Dahl, D.W. (2011), "It's the mind-set that matters: the role of construal level and message framing in influencing consumer efficacy and conservation behaviors", Journal of Marketing Research, Vol. 48 No. 3, pp. 472-485.

$\mathrm{Xu}$, J. and Huang, G. (2020), "The relative effectiveness of gain-framed and loss-framed messages in charity advertising: meta-analytic evidence and implications", International Journal of Nonprofit and Voluntary Sector Marketing, Vol. 25, e1675.

Yao, J., Chen, J., Wei, J., Chen, Y. and Yang, S. (2019), “The relationship between soft information in loan titles and online peer-to-peer lending: evidence from RenRenDai platform", Electronic Commerce Research, Vol. 19 No. 1, pp. 111-129.

Yin, R. (1983), "Case study reserach - design and methods", Applied Social Research Methods Series, Vol. 5.

Zhou, M., Zhang, X., Wang, A.G., Du, Q., Qiao, Z. and Fan, W. (2015), "Money talks: a predictive model on crowdfunding success using project description”, 2015 Americas Conference on Information Systems, AMCIS 2015.

Zubair, M., Wang, X., Iqbal, S., Awais, M. and Wang, R. (2020), "Attentional and emotional brain response to message framing in context of green marketing”, Heliyon, Vol. 6 No. 9, doi: 10.1016/ j.heliyon.2020.e04912. 


\section{About the authors}

Monica Rossolini is Associate Professor of Banking and Finance at the University of Milano-Bicocca, Department of Business and Law, where she lectures courses on Corporate Finance and Financial Markets. She holds a Master in Corporate Banking, University of Parma and a PhD in Banking and Finance at the University of Rome Tor Vergata. Her research interests and publications include fields such as SMEs financing, public credit guarantee schemes, fintech and financial literacy.

Alessia Pedrazzoli is PhD at Economics Department, University of Modena and Reggio Emilia. Her research interests include equity crowdfunding, entrepreneurial finance and new fintech instruments to support SMEs financing. Alessia Pedrazzoli is the corresponding author and can be contacted at: alessia. pedrazzoli@unimore.it

Alessandro Ronconi is Banker Consultant, Master's Graduate student in International Economics.
Greening crowdfunding campaigns

For instructions on how to order reprints of this article, please visit our website: 